\title{
Solvent Effects on Preparation of Pd-Based Catalysts: Influence on Properties of Palladium and Its Catalytic Activity for Benzyl Alcohol Oxidation
}

\author{
Feifei Wang*, Guifen Hao, Yuming Guo, Xiaoming Ma, Lin Yang \\ School of Chemistry and Chemical Engineering, Key Laboratory of Green Chemical Media and Reactions, \\ Ministry of Education, Henan Normal University, Xinxiang, China \\ Email: *wffmy@163.com
}

How to cite this paper: Wang, F.F., Hao, G.F., Guo, Y.M., Ma, X.M. and Yang, L. (2017) Solvent Effects on Preparation of Pd-Based Catalysts: Influence on Properties of Palladium and Its Catalytic Activity for Benzyl Alcohol Oxidation. Open Journal of Metal, 7, 59-68.

https://doi.org/10.4236/ojmetal.2017.74005

Received: November 10, 2017

Accepted: December 12, 2017

Published: December 15, 2017

Copyright $\odot 2017$ by authors and Scientific Research Publishing Inc. This work is licensed under the Creative Commons Attribution International License (CC BY 4.0).

http://creativecommons.org/licenses/by/4.0/

\begin{abstract}
Solvent effects are important for the solution preparation of nanoscale metal materials, in which the sizes and properties of the nanomaterials are greatly influenced by the solvents. In this study, a series of Pd/XC-72 catalysts were synthesized by a facile solvothermal method in solvents with different numbers of hydroxyl groups, including ethanol, ethylene glycol, and glycerine. The as-prepared catalysts $\mathrm{Pd} / \mathrm{XC}-72(\mathrm{EA}), \mathrm{Pd} / \mathrm{XC}-72(\mathrm{EG})$ and $\mathrm{Pd} / \mathrm{XC}-72(\mathrm{GI})$ were characterized by XRD, TEM, TGA, ICP-MS and multipoint nitrogen adsorption-desorption experiments. It was found that $\mathrm{Pd} / \mathrm{XC}-72(\mathrm{GI})$ had the highest metallic dispersion and the smallest particle size $(4.9 \mathrm{~nm})$. Furthermore, $\mathrm{Pd} / \mathrm{XC}$ 72(GI) exhibited the best catalytic performance for solvent-free selective oxidation of benzyl alcohol while the catalytic activities of Pd/XC-72 catalysts decreased in the order: $\mathrm{Pd} / \mathrm{XC}-72(\mathrm{GI})>\mathrm{Pd} / \mathrm{XC}-72(\mathrm{EG})>\mathrm{Pd} / \mathrm{XC}-72(\mathrm{EA})$.
\end{abstract}

\section{Keywords}

Palladium, Solvent Effects, Benzyl Alcohol Oxidation

\section{Introduction}

The selective oxidation of alcohols to the corresponding carbonyl compounds is an important functional group transformation in organic synthesis [1] [2] [3] [4]. Noble metals, especially Pd as the active components of heterogeneous catalysts, have been extensively investigated in recent years due to their effective catalytic abilities for the functional group transformation as good as their homogeneous 
counterparts [5] [6] [7] [8].

Among heterogeneous Pd catalysts, Pd catalysts supported on carbon materials such as $\mathrm{Pd} / \mathrm{XC}-72$ and $\mathrm{Pd} /$ graphite have been widely used for oxidation in the field of fine chemicals [9]. They have been proven to have many advantages as high efficiency catalysts due to their specific properties, such as acid and base resistance, porosity, and the possibility of recovering the metals by combustion of the supports [10] [11] [12] [13]. Hence, preparation of supported Pd catalyst with small Pd size and high catalytic activity is always an interesting topic. Previous research findings showed that sizes and morphology, and thus properties of heterogeneous Pd catalysts synthesized in solution, were influenced by Pd precursors [14], reaction temperature [15] and synthetic methods of catalysts [16] [17] [18] [19] [20]. Especially, an appropriate choice of the solvents as reducing agent is important in controlling the Pd particle size, because the reduction rate of $\left[\mathrm{PdCl}_{4}\right]^{2-}$ to $\mathrm{Pd}^{0}$ is greatly affected by the kind and the concentration of the reducing agent. Alba et al. [21] mentioned that glycerol as solvent and reducing agent for metal nanoparticles formation is clearly more convenient because of its lower cost and toxicity. Wool folk et al. [22] recently found that the NiWS catalyst activity could be improved upon the election of the solvents with different polar properties. However, the research about effects of alcohols as solvents on $\mathrm{Pd} / \mathrm{C}$ catalysts for solvent-free selective oxidation of benzyl alcohol is scare.

Therefore, the objective of this study is to compare the effect of solvents with different numbers of hydroxyl groups used for catalyst preparation on the properties of Pd/XC-72 catalysts, in particular on the catalytic activity and selectivity for solvent-free selective oxidation of benzyl alcohol. Eventually, among the three solvents studied, i.e., ethanol, ethylene glycol and glycerine, the most appropriate solvent would be determined. It is expected that this research may be of significance to synthesize Pd nanocatalysts with an appropriate solvent to improve their physicochemical properties and catalytic activities in solvent-free selective oxidation of alcohols with molecular oxygen.

\section{Experimental}

\subsection{Materials}

Palladium chloride $\left(\mathrm{PdCl}_{2}\right)$ was purchased from E. Merck AG Darmstadt. Other chemicals, including XC-72, ethanol $\left(\mathrm{C}_{2} \mathrm{H}_{6} \mathrm{O}, \mathrm{EA}\right)$, ethylene glycol $\left(\mathrm{C}_{2} \mathrm{H}_{6} \mathrm{O}_{2}, \mathrm{EG}\right)$, glycerine $\left(\mathrm{C}_{3} \mathrm{H}_{8} \mathrm{O}_{3}, \mathrm{GI}\right)$ and sodium hydroxide $(\mathrm{NaOH})$, were purchased from the China National Pharmaceutical Group Corp. All the chemicals were analytical grade and used without further purification. Double distilled water (DD water) was used throughout the experiments.

\subsection{Catalyst Preparation}

Synthesis of Pd/XC-72 catalysts with different solvents can be described as follows: an aqueous solution of $\mathrm{PdCl}_{2}\left(2 \mathrm{mg} \cdot \mathrm{mL}^{-1}, 2 \mathrm{~mL}\right)$ was added in $25 \mathrm{~mL}$ of 
solvent. The $\mathrm{pH}$ of the system was adjusted to ca.11 by adding dropwise an 8 wt\% $\mathrm{NaOH}$-solvent solution under vigorous stirring for $30 \mathrm{~min}$. Subsequently, $200 \mathrm{mg}$ of pristine Vulcan XC-72 (Cabot Corporation $200.6 \mathrm{~m}^{2} \cdot \mathrm{g}^{-1}$ ) were added, and the solution was ultrasonicated and stirred for $2 \mathrm{~h}$ to obtain a homogeneous suspension. Upon completion, the suspension was transferred into a $50 \mathrm{~mL}$ Teflon-lined stainless-steel autoclave. The autoclave was sealed, heated at $403 \mathrm{~K}$ for $3 \mathrm{~h}$, and air-cooled to room temperature. Then, the product was collected by filtration and washed several times with doubly distilled water. Finally, the obtained solid was dried at $313 \mathrm{~K}$ under vacuum for $8 \mathrm{~h}$. According to the solvents used, the samples were respectively named: $\mathrm{Pd} / \mathrm{XC}-72(\mathrm{EA}), \mathrm{Pd} / \mathrm{XC}-72(\mathrm{EG})$ and $\mathrm{Pd} / \mathrm{XC}-72(\mathrm{GI})$.

\subsection{Characterization}

TEM (Transmission Electron Microscope) images were obtained using a JEOL JEM-2100 operated at $200 \mathrm{kV}$. The samples were suspended in ethanol and dispersed on a holey carbon-coated $\mathrm{Cu}$ gird. The XRD (X-ray Diffraction) patterns were recorded on a Bruker D8 Advance diffractometer under ambient conditions using filtered $\mathrm{Cu}-\mathrm{Ka}$ radiation $(\lambda=0.15406 \mathrm{~nm})$ operated at $40 \mathrm{kV}$ and 40 $\mathrm{mA}$, and a scanning rate of $0.051 \mathrm{~s}^{-1}$ was applied to collect diffraction data from $15^{\circ}$ to $90^{\circ}$. The TGA (Thermal Gravity Analysis) were performed on an EXSTAR TG/DTA 6300 system at a heating rate of $10^{\circ} \mathrm{min}^{-1}$ from $293 \mathrm{~K}$ to $1173 \mathrm{~K}$. The compositions of the Pd/XC-72 catalysts were evaluated by ICP-MS (Inductively Coupled Plasma-Mass Spectrometry) analysis after the sample was dissolved in a nitrohydrochloric acid solution. Multipoint nitrogen adsorption-desorption experiments were carried out by means of an automatic Micromeritics ASAP 2020 analyzer using the Brunauer-Emmett-Teller (BET) gas adsorption method.

\subsection{Alcohol Catalytic Oxidation}

The catalytic oxidation of benzyl alcohol was carried out using the following procedures. $0.1 \mathrm{~g}$ catalyst was added into the alcohol, and the mixture was then heated to the reaction temperature with vigorous stirring. Then an $\mathrm{O}_{2}$ gas flow was bubbled into the mixture to start the reaction. After the reaction, the solid catalyst was filtered off and the liquid products were analyzed after the addition of an internal standard by an Agilent gas chromatograph (GC) 6890 equipped with a flame ionization detector and a DB-5 capillary column (30 m long and 0.25 $\mathrm{mm}$ in diameter).

\section{Results and Discussion}

In the current study, the structure and crystallographic planes of the catalysts were analyzed by XRD. Figure 1 shows the XRD patterns of the as-prepared catalysts. All samples show three peaks at $2 \theta=40.1^{\circ}, 46.7^{\circ}$, and $68.1^{\circ}$, which can be assigned to (111), (200) and (220) planes of face-centered-cubic Pd (JCPDS card no: 46-1043), respectively. We noted that the Pd (111) reflection of $\mathrm{Pd} / \mathrm{XC}-72(\mathrm{GI})$ 


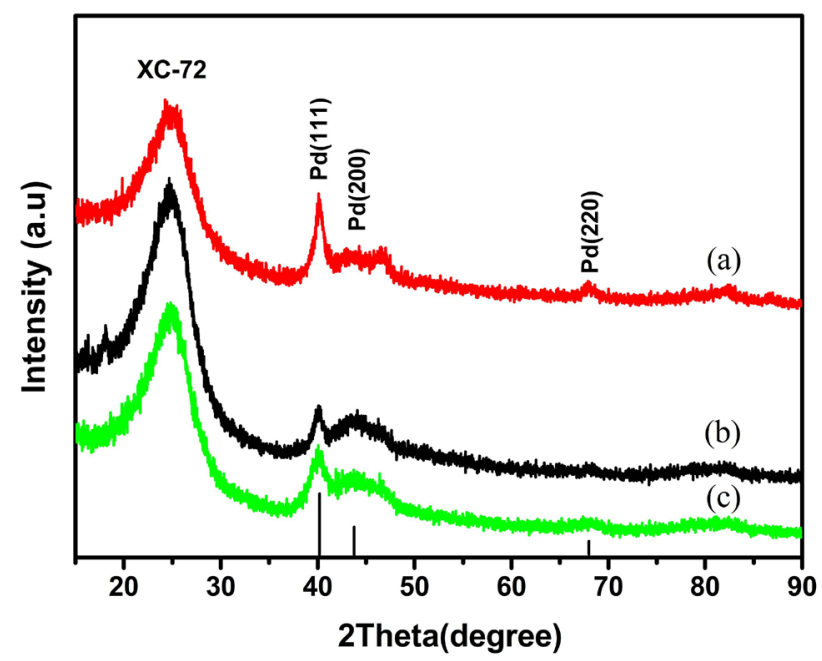

Figure 1. XRD patterns of (a) Pd/XC-72(EA); (b) Pd/XC-72(EG) and (c) Pd/XC-72(GI). The upright black lines represent respective standard peaks (JCPDS card no: 46-1043).

(curve c) showed broader and weaker diffraction than that of Pd/XC-72(EA) (curve a) and Pd/XC-72(EG) (curve b), which suggested that smaller Pd nanoparticles are prepared in a highly dispersed state with the addition of glycerine. This statement can be supported by the data extracted from XRD analysis in Table 1. We know that Scherrer's equation that relies on the FWHM (full width at half maximum) of the diffraction peaks can be helpful in gaining an estimation of the nanoparticle size. So, the calculation results according to Scherrer's equation generally indicate that $\mathrm{Pd}$ nanoparticles of $\mathrm{Pd} / \mathrm{XC}-72(\mathrm{GI})$ has the smallest particle size, which have similar results to that obtained from the TEM images (Figure 2).

Figure 2 shows the typical TEM images of Pd/XC-72 samples fabricated using different solvents. The corresponding particle size distributions derived from the TEM micrographs by counting ca. 100 particles are also shown in Figure 2. Figure 2(a) displays the TEM image of Pd/XC-72(EA). It can be found that the Pd nanoparticles of $\mathrm{Pd} / \mathrm{XC}-72(\mathrm{EA})$ were big and aggregated in certain regions of the support. Moreover, the large and irregular particles with the average size of 13.2 $\mathrm{nm}$ were obtained in the presence of EA (Figure 2(b)). Figure 2(c) shows the TEM image of Pd/XC-72(EG). It shows that Pd nanoparticles with the average diameter of about $7.6 \mathrm{~nm}$ (shown in Figure 2(d)) were not evenly dispersed on the entire surface of XC-72. For the catalyst Pd/XC-72(GI) (Figure 2(e)), small Pd nanoparticles with the average size of $4.9 \mathrm{~nm}$ (see Figure 2(f)) were uniformly dispersed on the surface of the XC-72 support in the presence of glycerine. These results indicate that the size and dispersion of Pd nanoparticles on XC-72 can indeed affected by the solvents when using the same Pd precursor under the identical preparation condition. From the viewpoint of the kind of alcohol, the particle size become smaller in the order of ethanol > ethylene glycol > glycerine; this tendency corresponds to their increasing boiling points. Thus, it is suggested 
Table 1. Structural data extracted from XRD analysis.

\begin{tabular}{cccc}
\hline Sample & Peak height of Pd (111) (A.U) & Peak FWHM of Pd $(111)\left({ }^{\circ}\right)$ & Crystallite size from Scherrer's equation $(\mathrm{nm})$ \\
\hline Pd/XC-72(EA) & 312 & 0.73 & 11.2 \\
Pd/XC-72(EG) & 157 & 1.01 & 8.1 \\
Pd/XC-72(GI) & 146 & 1.31 & 6.2 \\
\hline
\end{tabular}
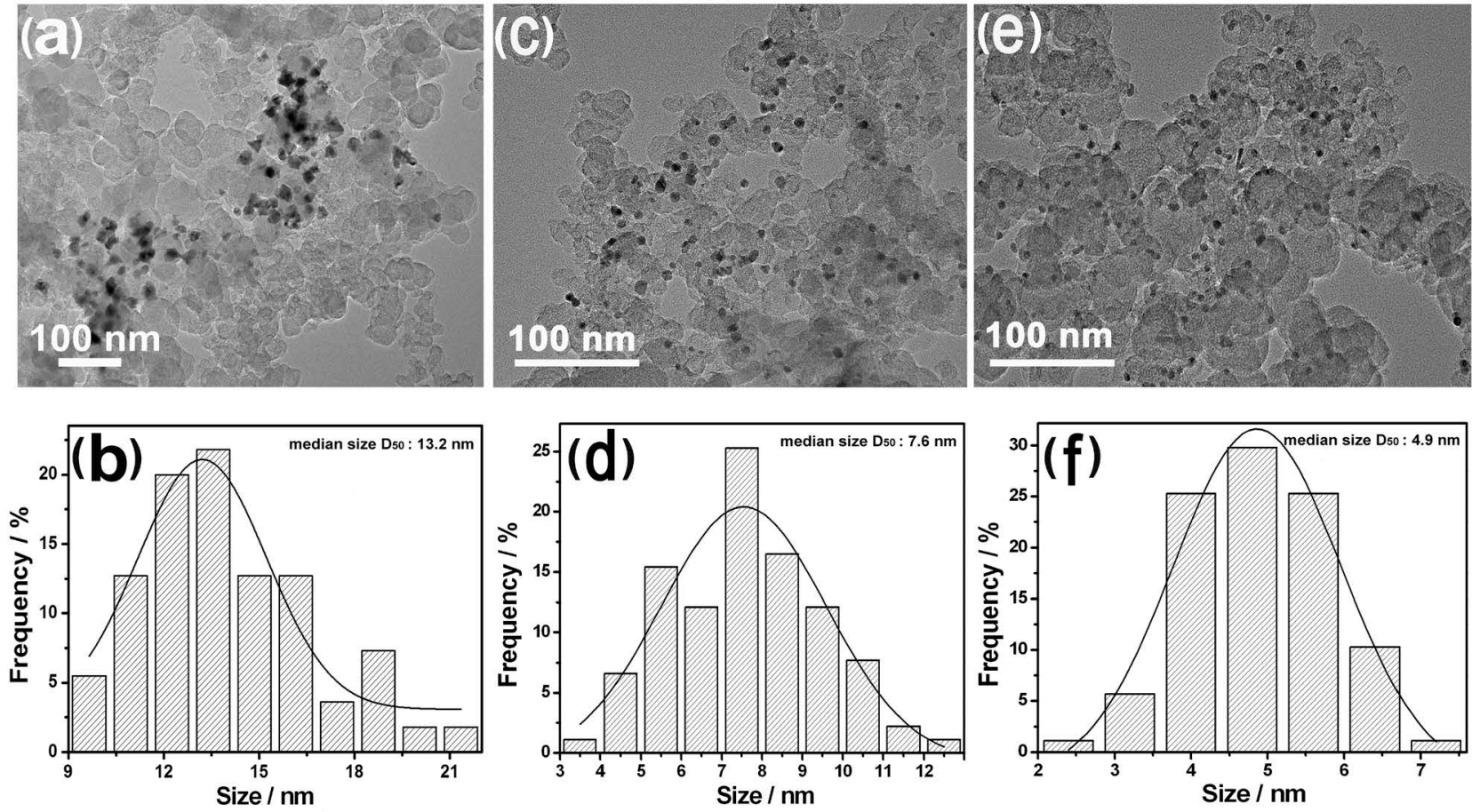

Figure 2. TEM images and particle size distributions of (a); (b) Pd/XC-72(EA); (c) (d) Pd/XC-72(EG); and (e) (f) Pd/XC-72(GI).

that the reduction of $\left[\mathrm{PdCl}_{4}\right]^{2-}$ by the alcohol with higher boiling point produces more Pd nuclei in a shorter period and suppresses the growth of Pd nanoparticles, that is, a faster reduction rate of $\left[\mathrm{PdCl}_{4}\right]^{2-}$ is needed to generate the smaller $\mathrm{Pd}$ nanoparticles with narrower distribution [23].

All samples were characterized by TGA under a $\mathrm{N}_{2}$ atmosphere (Figure 3) to demonstrate whether the catalysts contained residual solvents. As shown in curve a, there is no significant mass loss in XC-72 from $293 \mathrm{~K}$ to $1173 \mathrm{~K}$, suggesting that there are nearly no other additives on the XC-72 support. However, a mass loss of about $1.2 \%$ (curve b), 3.7\% (curve c), and 4.3\% (curve d), can be respectively observed in Pd/XC-72(EA), Pd/XC-72(EG) and Pd/XC-72(GI) from $293 \mathrm{~K}$ to $1173 \mathrm{~K}$. According to the solvents boiling points, it can be presumed that the mass loss may be attributed to the decomposition of residual solvents ( $293 \mathrm{~K}$ to $563 \mathrm{~K}$ ) and traces of inorganic salts ( $563 \mathrm{~K}$ to $1173 \mathrm{~K}$ ).

The BET surface areas of the Pd-based catalysts together with pure Vulcan XC-72 are summarized in Table 2. Compared with Vulcan XC-72, the surface area of all the catalysts obviously decreased, which might be attributed to the deposition of Pd nanoparticles on the outer surface of the support fills the pores of the XC-72. 


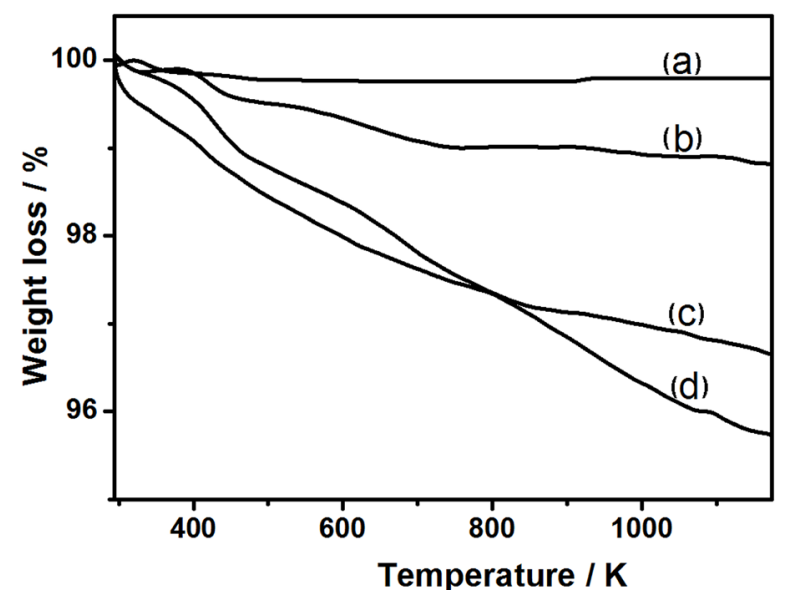

Figure 3. TGA curves of (a) XC-72; (b) Pd/XC-72(EA); (c) $\mathrm{Pd} / \mathrm{XC}-72(\mathrm{EG})$; and (d) Pd/XC-72(GI). All the experiments were conducted under a $\mathrm{N}_{2}$ atmosphere.

Table 2. BET surface areas for different catalysts.

\begin{tabular}{ccc}
\hline Sample & $S_{B E T}^{a}\left(\mathrm{~m}^{2} \cdot \mathrm{g}^{-1}\right)$ & $V_{t}^{b}\left(\mathrm{~cm}^{3} \cdot \mathrm{g}^{-1}\right)$ \\
\hline XC-72 & 200.6 & 0.51 \\
Pd/XC-72(EA) & 179.7 & 0.48 \\
Pd/XC-72(EG) & 133.8 & 0.41 \\
Pd/XC-72(GI) & 101.7 & 0.36 \\
\hline
\end{tabular}

The change of BET surface area of $\mathrm{Pd} / \mathrm{XC}-72(\mathrm{EA})$ is not significant probably because of its low Pd loading and large Pd particle size. For the Pd/XC-72(GI) catalyst, its BET surface area significantly dropped from $200.6 \mathrm{~m}^{2} \cdot \mathrm{g}^{-1}$ to 101.7 $\mathrm{m}^{2} \cdot \mathrm{g}^{-1}$. This result can be due to two reasons: 1) the pores in the XC-72 are partially filled by the small Pd nanoparticles with the average size of $4.9 \mathrm{~nm} ; 2$ ) the solvent glycerine may affect the surface properties of the support and probably fill its pore of Vulcan XC-72. The adsorption and desorption of reactants and products respectively, and the diffusion process will influence the catalytic properties. Consequently, the surface area and pore volume significantly affect catalytic properties [24].

The catalytic performance of different $\mathrm{Pd} / \mathrm{XC}-72$ catalysts was investigated and the results are shown in Table 3. Irrespective of the different solvents, all the catalysts show rather high selectivity to benzaldehyde (99\%). However, the catalytic activities are influenced by using different solvents during catalysts preparation. For the $\mathrm{Pd} / \mathrm{XC}-72$ (EA), only about $20.7 \%$ of benzyl alcohol conversion was obtained, and it had the lowest TOF value $\left(368 \mathrm{~h}^{-1}\right)$. A higher TOF value (566 $\mathrm{h}^{-1}$ ) could be achieved over Pd/XC-72(EG). The Pd/XC-72(GI) catalyst showed the highest conversion of benzyl alcohol (almost $90 \%)$ and TOF value $\left(796 \mathrm{~h}^{-1}\right)$. It is reported that smaller Pd particles with high dispersion containing more coordinately unsaturated Pd sites are generally believed to be more active for many 
Table 3. Physico-chemical and catalytic properties of the Pd/XC-72 catalysts ${ }^{\mathrm{a}}$.

\begin{tabular}{cccccc}
\hline Catalysts & $\begin{array}{c}\text { Total metal } \\
\text { loading(wt\%) }\end{array}$ & $\begin{array}{c}\text { Average Pd particle } \\
\text { size }(\mathrm{nm})^{\mathrm{c}}\end{array}$ & Conv. (\%) & Select. (\%) & ${\text { TOF }\left(\mathrm{h}^{-1}\right)^{\mathrm{d}}}^{\mathrm{b}}$ \\
\hline Pd/XC-72(EA) & 0.9 & 13.2 & $20.7 \%$ & $>99$ & 368 \\
Pd/XC-72(EG) & 1.9 & 7.6 & $67.2 \%$ & $>99$ & 566 \\
Pd/XC-72(GI) & 1.8 & 4.9 & $89.6 \%$ & $>99$ & 796 \\
\hline
\end{tabular}

${ }^{a}:$ Reaction conditions: catalyst $=0.1 \mathrm{~g}$; benzyl alcohol $=5 \mathrm{~mL} ; \mathrm{O}_{2}$ flow rate $=20 \mathrm{~mL} \cdot \mathrm{min}^{-1} ; \mathrm{T}=403 \mathrm{~K}$; reaction time $=3 \mathrm{~h} .^{b}$ : Atomic ratios of Pd to $\mathrm{Cu}$ determined by ICP-MS. ${ }^{c}$ : Average particle sizes estimated by TEM images. ${ }^{\mathrm{d}}:$ TOF $=$ turn-over frequency.

Pd catalyzed organic reactions [25]. For the aerobic oxidation of alcohols over palladium-based catalyst, the particle size of palladium is also a key factor to influence its catalytic activity. Wang et al. [26] studied the palladium catalyst with tunable size in a range of $2-5 \mathrm{~nm}$ possess good catalytic activities for the oxidation of alcohols. Therefore, the good catalytic performance of Pd/XC-72(GI) for the oxidation of alcohol can be attributed to the small size and the good dispersion on the support.

To better understand the formation of $\mathrm{Pd} / \mathrm{XC}-72$ catalysts, a possible mechanism was presented for the preparation of Pd nanoparticles supported on XC-72 by the facile solvothermal method in Scheme 1. Firstly, three different kinds of alcohols, as both solvents and mild reducing agents, were mixed with $\mathrm{Pd}^{2+}$ respectively. Subsequently, these $\mathrm{Pd}^{2+}$ ions were reduced by alcohols during the solvothermal reaction to form Pd nanoparticles. Based on the TEM data, one can draw a conclusion that the synthesis of highly stable small monodisperse populations of palladium nanoparticles with $4.9 \mathrm{~nm}$ in size was achieved via glycerine. Because the reduction of $\left[\mathrm{PdCl}_{4}\right]^{2-}$ by the alcohol with higher boiling point produces more Pd nuclei in a shorter period and suppresses the growth of Pd nanoparticles. Moreover, according to the results of TGA and ICP-MS, the final molar ratio of $\mathrm{Pd}$ nanoparticles and residual solvent in the respective $\mathrm{Pd} / \mathrm{XC}-72$ catalysts is the same. Therefore, glycerine molecules with three hydroxyl groups and high boiling point might be beneficial to stabilize the palladium nanoparticles over a long period, prompting the formation of small Pd nanoparticles with good dispersion and fine homogeneity.

\section{Conclusion}

A series of Pd/XC-72 catalysts were synthesized by a one-step solvothermal method using different solvents including ethanol, ethylene glycol, and glycerine. Catalysts were evaluated by solvent-free selective oxidation of benzyl alcohol at $403 \mathrm{~K}$, and showed different catalytic activities. Among three catalysts, Pd/XC-72 (GI) with good dispersion and small Pd nanoparticles size has highly efficient in the solvent-free oxidation of benzyl alcohol with molecular oxygen. It is considered that the solvents, which are applied to dissolve Pd precursors, remarkably influence the interaction between the Pd nanoparticles and the supports. Meanwhile, the groups from solvents may prohibit the sintering of supported Pd during the 


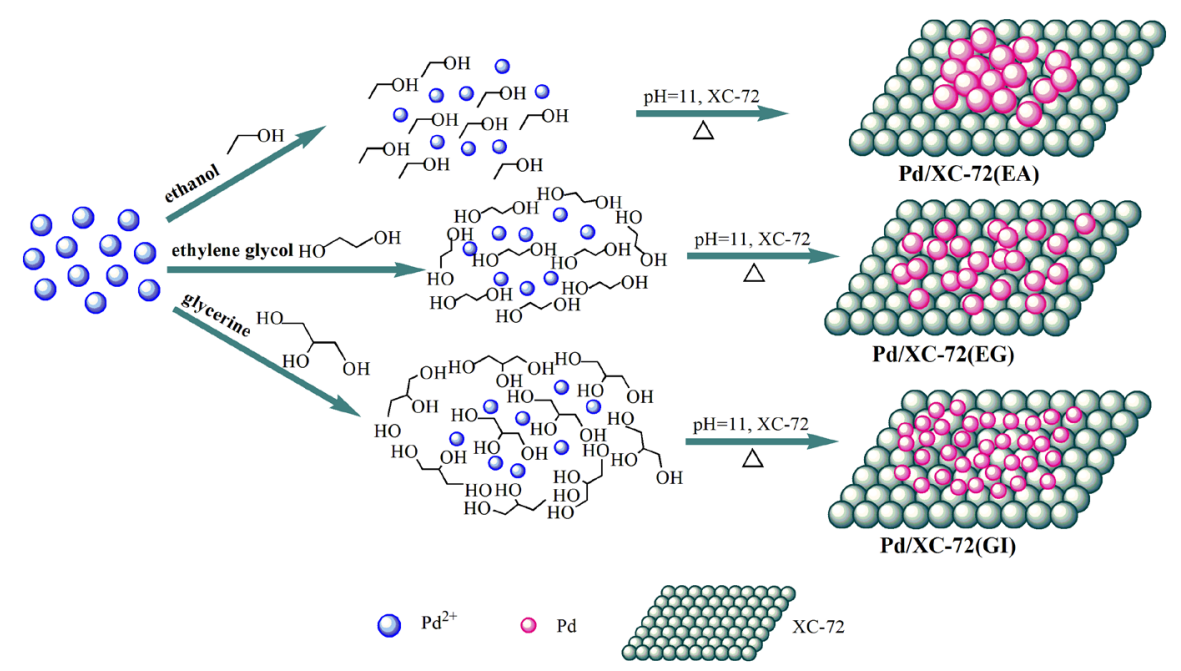

Scheme 1. Possible formation mechanisms of the as-prepared Pd/XC-72 catalysts.

catalyst synthesis process, which can influence the size, shape and dispersity of Pd nanoparticles. These results may improve our understanding of solvent effects during the preparation of Pd-based catalysts, and help us explore new ways in practical demands in many industries and labs as well as academic research interesting for design Pd-based nanocatalysts with increased effectiveness and relatively low cost.

\section{Acknowledgements}

This work was financially supported by the Doctoral Scientific Research Foundation of Henan Normal University (5101039170128), the National Science Foundation of China (grant no. 21171051), the National Science Foundation of China (grant no. 21271066); and the NFSC-Henan Talent Training United Fund (grant no. U1204519).

\section{References}

[1] Mallat, T. and Baiker, A. (2004) Oxidation of Alcohols with Molecular Oxygen on Solid Catalysts. Chemical Reviews, 104, 3037-3058.

https://doi.org/10.1021/cr0200116

[2] Enache, D.I., Edwards, J.K., et al. (2006) Solvent-Free Oxidation Primary Alcohols to Aldehydes Using Au-Pd/TiO ${ }_{2}$ Catalysts. Science, 311, 362-365.

https://doi.org/10.1126/science.1120560

[3] Harada, T., Ikeda, S., et al. (2010) Catalytic Activity and Regeneration Property of a Pd Nanoparticle Encapsulated in a Hollow Porous Carbon Sphere for Aerobic Alcohol Oxidation. Langmuir, 26, 17720-17725. https://doi.org/10.1021/la102824s

[4] Poliakoff, M., Fitzpatrick, J.M., Farren, T.R. and Anastas, P.T. (2002) Green Chemistry: Science and Politics of Change. Science, 297, 807-810.

https://doi.org/10.1126/science.297.5582.807

[5] Zhang, P.F., Gong, Y.T., Li, H.R., Chen, Z.R. and Wang, Y. (2013) Solvent-Free Aerobic Oxidation of Hydrocarbons and Alcohols with Pd@N-Doped Carbon from Glucose. Nature Communications, 4, 1593. https://doi.org/10.1038/ncomms2586 
[6] Liu, J., Yang, H.Q., et al. (2012) Yolk-Shell Hybrid Materials with a Periodic Mesoporous Organosilica Shell: Ideal Nanoreactors for Selective Alcohol Oxidation. Advanced Functional Materials, 22, 591-599. https://doi.org/10.1002/adfm.201101900

[7] Hao, Y., Wang, S., Sun, Q., Shi, L. and Lu, A.H. (2015) Uniformly Dispersed Pd Nanoparticles on Nitrogen-Doped Carbon Nanospheres for Aerobic Benzyl Alcohol Oxidation. Chinese Journal of Catalysis, 36, 612-619. https://doi.org/10.1016/S1872-2067(14)60274-6

[8] Zhang, H. Xie, Y.Z. et al. (2011) In-Situ Loading Ultrafine AuPd Particles on Ceria: Highly Active Catalyst for Solvent-Free Selective Oxidation of Benzyl Alcohol. Langmuir, 27, 1152-1157. https://doi.org/10.1021/la1034728

[9] Marjolein, L.T., Jos, A.D. and Krijn, P.J. (2001) Synthesis of supported Palladium Catalysts. Journal of Molecular Catalysis A: Chemical, 173, 75-98. https://doi.org/10.1016/S1381-1169(01)00146-7

[10] Auer, E., Freund, A., Pietsch, J. and Tacke, T. (1998) Carbons as Supports for Industrial Precious Metal Catalysts. Applied Catalysis A: General, 173, 259-271. https://doi.org/10.1016/S0926-860X(98)00184-7

[11] Lin, Y., Baggett, D.W., Kim, J.W., Siochiand, E.J. and Connell, J.W. (2011) Instantaneous Formation of Metal and Metal Oxide Nanoparticles on Carbon Nanotubes and Graphene via Solvent-Free Microwave Heating. ACS Applied Materials \& Interfaces, 3, 1652-1664. https://doi.org/10.1021/am200209e

[12] Yu, D., Bai, J., Wang, J., Liang, H. and Li, C. (2017) Assembling Formation of Highly Dispersed Pd Nanoparticles Supported 1D Carbon Fiber Electrospun with Excellent Catalytic Active and Recyclable Performance for Suzuki Reaction. Applied Surface Science, 399, 185-191. https://doi.org/10.1016/j.apsusc.2016.12.065

[13] Besson, M., Lahmer, F., Gallezot, P., Fuertes, P. and Fleche, G. (1995) Catalytic Oxidation of Glucose on Bismuth-Promoted Palladium Catalysts. Journal of Catalysis, 152, 116-121. https://doi.org/10.1006/jcat.1995.1065

[14] Kinnunen, N.M., Suvanto, M., et al. (2009) Methane Oxidation on Alumina Supported Palladium Catalysts: Effect of Pd Precursor and Solvent. Applied Catalysis A: General, 370, 78-87. https://doi.org/10.1016/j.apcata.2009.09.018

[15] Niu, W., Zhang, L. and Xu, G. (2010) Shape-Controlled Synthesis of Single-Crystalline Palladium Nanocrystals. ACS Nano, 4, 1987-1996.

https://doi.org/10.1021/nn100093y

[16] Wang, F., Yang, L., Tang, Q., Guo, Y. and Hao, G. (2013) Synthesis of Pd/XC-72 Catalysts by a Facile Glutamate-Mediated Method for Solvent-Free Selective Oxidation of DL-Sec-Phenethyl Alcohol. Catalysis Science \& Technology, 3, 1246-1252. https://doi.org/10.1039/c3cy20803f

[17] Aasiya, S. and Smrutiranjan, P. (2016) Facile Sonochemical Synthesis of Highly Dispersed Ultrafine Pd Nanoparticle Decorated Carbon Nano-Onions with High Metal Loading and Enhanced Electrocatalytic Activity. RSC Advances, 6, 83711-83719. https://doi.org/10.1039/C6RA18190B

[18] Rather, S., Zacharia, R., Hwang, S.W., Naik, M. and Nahm, K.S. (2007) Hydrogen Uptake of Palladium-Embedded MWCNTs Produced by Impregnation and Condensed Phase Reduction Method. Chemical Physics Letters, 441, 261-267. https://doi.org/10.1016/j.cplett.2007.05.006

[19] Carrettin, S., McMorn, P., Johnston, P., Griffin, K., Kiely, C.J. and Hutchings, G.J. (2003) Oxidation of Glycerol using Supported Pt, Pd and Au Catalysts. Physical Chemistry Chemical Physics, 5, 1329-1336. https://doi.org/10.1039/b212047j 
[20] Harada, T., Ikeda, S., Miyazaki, M., Sakata, T., Mori, H. and Matsumura, M. (2007) A Simple Method for Preparing Highly Active Palladium Catalysts Loaded on Various Carbon Supports for Liquid-Phase Oxidation and Hydrogenation Reactions. Journal of Molecular Catalysis A: Chemical, 268, 59-64. https://doi.org/10.1016/j.molcata.2006.12.010

[21] Alba, E.D. and Victorio, C. (2013) Glycerol: A Promising Green Solvent and Reducing Agent for Metal-Catalyzed Transfer Hydrogenation Reactions and Nanoparticles Formation. Applied Sciences, 3, 55-69. https://doi.org/10.3390/app3010055

[22] Woolfolka, L.G., Geantetb, C., Massinb, L., Laurentib, D. and Reyesa, J.A.D. (2017) Solvent Effect over the Promoter Addition for a Supported NiWS Hydrotreating Catalyst. Applied Catalysis B: Environmental, 201, 331-338.

https://doi.org/10.1016/j.apcatb.2016.07.052

[23] Teranishi, T. and Miyake, M. (1998) Size Control of Palladium Nanoparticles and Their Crystal Structures. Chemistry of Materials, 10, 594-600. https://doi.org/10.1021/cm9705808

[24] Shen, X., Dai, M., Gao, M., Zhao, B. and Ding, W. (2013) Solvent Effects in the Synthesis of CoB Catalysts on Hydrogen Generation from Hydrolysis of Sodium Borohydride. Chinese Journal of Catalysis, 34, 979-985.

https://doi.org/10.1016/S1872-2067(12)60577-4

[25] Han, Y.F., Kumar, D. and Goodman, D.W. (2005) Particle Size Effects in Vinyl Acetate Synthesis over $\mathrm{Pd} / \mathrm{SiO}_{2}$. Journal of Catalysis, 230, 353-358. https://doi.org/10.1016/j.jcat.2004.12.018

[26] Li, F., Zhang, Q. and Wang, Y. (2008) Size Dependence in Solvent Free Aerobic Oxidation of Alcohols Catalyzed by Zeolite Supported Palladium Nanoparticles. Applied Catalysis A, 334, 217-226. https://doi.org/10.1016/j.apcata.2007.10.008 